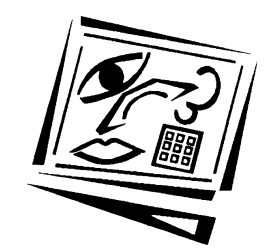

\title{
Computer-based concept maps for enabling multilingual education in computer science: A Basque, English and Spanish languages case
}

\author{
Ana Arruarte, Jon A. Elorriaga, Iñaki Calvo, Mikel Larrañaga \\ University of the Basque Country, Spain \\ Urko Rueda \\ Universitat Politècnica de València, Spain
}

\begin{abstract}
Inside the globalisation era in which society is immersed, one of the current challenges for any educational system is to provide quality education. While some countries are linguistically homogeneous, many countries and regions display a wealth of linguistic diversity and it is essential to adapt the educational system to those realities. In addition, multilingual education promotes not only social equality but also intercultural education. The development of computer software localisable not only at interface level but also regarding learning resources may help to fulfill this aim. During the last years a number of products have emerged to support computer-based concept mapping. This paper presents a pilot study carried out at the University of the Basque Country UPV/EHU in the area of database systems with three main aims: to facilitate learning about the subject domain, to evaluate whether concept mapping is in general a good technique for learning topics in different languages, and finally, to verify whether CM-ED Concept Map EDitor provides the necessary mechanisms to fulfil this objective. Results confirm that the use of a concept map editor is a good support for education in multilingual settings.
\end{abstract}

\section{Introduction}

In the current era of globalisation, bilingual and even multilingual contexts, i.e. the presence of different linguistic groups living in the same country, are the norm rather that the exception (Unesco, 2003). While some countries are linguistically homogeneous, many countries and regions display a wealth of linguistic diversity. Nowadays, the use of more than one language in daily life, bilingualism and multilingualism, is a normal practice. In this context, the challenge for education systems is to adapt to these realities and provide quality education. Some governments are becoming conscious that it is necessary to deal with the diversity in language, culture and identity. The way that human beings communicate with each other is primarily through language. The language of instruction in schools and universities refers to the language used for teaching the basic curriculum of the educational system. Nevertheless, bilingual and multilingual education - the use of two or more languages as a medium of instruction - promotes not only social equality but also inter-cultural education. Even more, language skills can help to open doors to better jobs or to international markets. 
On the other hand, in some subject areas such as computer science, most of the world's languages, with the exception of the English language, are minority languages. The technical terminology that people use all over the world is mainly English. Due to the status of English in computing, software development nearly always requires using it.

Concept mapping is a technique that allows information visualisation. A concept map (CM) is a graphical way of representing and organising knowledge (Novak, 1992). Many studies had validated the appropriateness of the concept mapping technique to fulfill different educational purposes: to support learning, to assess learning, and to organise and present information for teaching and learning. Nevertheless, few studies that investigate the validity of concept maps to learn content topics in different languages are publicly available.

During recent years, and due mainly to the innovation of visual design software (Dabbagh, 2001), a number of products have emerged to support computer-based concept mapping. This kind of software enables much easier production and modification of concept maps (Jonassen et al., 1997). Anderson-Inman, Ditson and Ditson (1998) argued that the practical advantages of constructing concept maps electronically are similar to those of using a word processing program for writing. There is easy construction and revision, and scope to customise maps in ways that are not possible with paper and pencil.

This paper presents a study carried out with the aim of validating the CM-ED Concept Map Editor as a tool useful in learning a subject in different languages is presented. The paper starts with an introduction of the concept mapping technique and a description of CM-ED mechanisms for working with multilingual concept maps. Then, research design issues and procedures for the study are presented. Next, the results of the study are analysed and discussed. Finally, conclusions and future research are presented.

\section{Concept mapping}

A concept map is a diagram showing the relationships among concepts. Concept maps are graphical tools for organising and representing knowledge (Novak \& Cañas, 2008). They include nodes (concepts), usually enclosed in circles or boxes, and relationships between concepts, connection lines linking at least two concepts that establish propositions. Both nodes and links can be labeled with a key or brief text that adds semantic to them. Concept maps have their origin in the learning movement called constructivism. The concept mapping technique was developed by Joseph D. Novak and his research team at Cornell University in the 1970s (Novak, 1977). The fundamentals of concept mapping are in Ausubel's learning and assimilation theories. The former is based on the assumption that meaningful learning occurs when the new concepts are linked to familiar concepts existing in the learner's cognitive structure (Ausubel, 1968). The latter is sustained in the hierarchical structure of a concept map from an abstract level to a more specific level helping in the comprehensiveness of the information (Ausubel et al., 1978).

The concept mapping technique has been much discussed in the literature. Although concept maps are used in areas such as education, business, industry and military, education constitutes the root of concept maps and, still today, this area is the main test bed. Inside the educational area concept maps had been mainly used to support learning, to assess learning, and to organise and present information. 
As a tool to support learning, some uses included concept maps as a scaffold to understand or to consolidate educational experiences, as a medium to improve affective conditions for learning, as an aid or alternative to traditional writing, and as a way to improve critical thinking. They are more useful for visual learners who can memorise information contained in a picture and for learners who have good synthesis skills (Cicognani, 2000). Some studies were addressed to evaluate the effect of concept maps on students' achievements in technical areas such as science: ecology and genetics (Esiobu \& Soyibo, 1995), diffusion and osmosis (Tekkaya, 2003), physics (Taber, 1994), chemistry (Brandt et al., 2001), maths (Afamasaga-Fuata'i, 2004), economics (Marangos \& Alley, 2007), therapeutic education (Marchand et al., 2002), pharmacology (Laight, 2004), nursing education (Hsu \& Hsieh, 2005; Gul \& Boman, 2006), weathering, the nature of soil, soil erosion, erosion by gravity, and erosion by winds (Know \& Cifuenttes, 2009), computer science (Calvo et al., 2011) and in theoretical areas such as psychology (Rueda et al., 2009; Elorriaga et al., 2011) or vocabulary teaching (Wilson et al., 2010).

With respect to learning assessment using concept maps, they can be used in formative or summative assessment procedures in order to evaluate student learning and knowledge acquisition. In formative assessment, teachers can use the maps generated by students to better understand their learning, in order to plan future learning activities. Summative assessment can be used to determine the learner's understanding of a unit. Ruiz-Primo (2004) worked on issues related to the development and technical examination of concept maps as assessment tools. She focused on some of the dimensions that can be used to define the assessment task and described concept maps as assessment tools for measuring the organisation of declarative knowledge of a domain. Some studies focused on assessment of learning in different areas using concept maps have been carried out, for example in physics (Austin \& Shore, 1995), mathematics (Roberts, 1999) and marine science (Stoddart et al., 2000).

Finally, regarding information organisation and presentation, concept maps can be used as advance organisers, as aids for course and curriculum development, and as a means to provide navigation support. Some studies, for example Arbea et al. (2004) explored the possibilities that CmapTools offer to create and navigate through subordinated concept maps. The model has the advantage of being open and modifications and expansions are allowed at any time. In other work concept maps were used as a medium to organise all the learning resources (theoretical contents, laboratories, exercises, etc) related to the "Introduction to Artificial Intelligence" subject (Arruarte et al., 2008). In literature area Carnot (2006) presented the benefit of using concept maps as a way of structuring large collections of information.

Few studies investigating the validity of concept maps to learn topics in different languages are publicly available. Regarding second language acquisition Chularut and DeBacker (2004) investigated the effectiveness of concept mapping used as a learning strategy for learning English from texts (72 students participated in the study). For four outcome variables - achievement when learning from English-language texts, self-regulation, knowledge acquisition, and self-efficacy - the concept mapping group showed significantly greater gains from pre-test to post-test that the control group (individual study plus discussion group). In the study carried out by Bahr and Dansereau (2004) 38 undergraduates students participated in an experiment developed with the aim of investigating the potential of bilingual concept maps for foreign language vocabulary study. Although results obtained for 32 word-pairs were encouraging and the use of bilingual concept maps appeared to facilitate recall, the 
authors indicated that more studies were needed. Later, the same authors (Bahr \& Danserau, 2005) carried out a study that involved 82 undergraduate students from psychology in the task of studying 32 German-English word pairs. Students who used Bilingual Knowledge Maps (BiK Maps) showed greater recall than the control group and reported greater use of breadth-based recall strategies. Reza and Mausapour (2009) investigated the effectiveness of concept mapping as a learning strategy on EFL (English as a foreign language) students' self-regulation. Sixty university students participated in the study and the findings revealed that students gained higher selfregulation in writing tasks as a result of explicit instruction with the concept mapping strategy.

In foreign language education concept maps were also used in an attempt to help students organise, interact, and share meanings derived from their reading of literacy texts in the American literature discipline (Moreira \& Moreira, 2011). The linkages between concept maps and language learning were explored by Trong and Bich (2011): concept mapping as a form of pre-task planning, concept maps to facilitate knowledge acquisition via meaningful learning, concept mapping as a strategy to evaluate critical thinking as a learning outcome, concept mapping as a means to facilitate reading comprehension, and finally, concept maps to enrich classroom discourse. The findings of the work carried out by Mahnam and Najafabab (2012) revealed the positive effects of using concept maps as a pre-writing strategy on EFL writing achievement. Students in the experimental group of a study performed with twenty three adult EFL students from Iran at the advanced level of language proficiency attended to writing tasks and controlled their learning more effectively than students in the control group. In a similar investigation, again in Iran, the impact of concept mapping as a form of pretask on use of tenses in oral accuracy was reported by Saadati (2011).

\section{Multilingual concept mapping in CM-ED}

CM-ED (Concept Map EDitor) is a flexible multilingual tool for editing concept maps. It was developed by the Ga-Lan research group (http://galan.ehu.es/) whose research focuses on flexible educational environments for promoting teaching and learning. Software can be downloaded from Ga-Lan (http:/ / galan.ehu.es/Galan/products). The aim of the tool is to be useful in different contexts and uses, CM-ED being a multilingual tool localisable not only at user interface level but also regarding the concept maps it generates. CM-ED offers a flexible way for building multilingual concept maps. It provides some mechanisms like simultaneous work with different versions, the propagation of changes, the control of changes, and the dictionary.

- Simultaneous work with different versions. When the user wants to create a multilingual concept map s/ he creates a view for each different language. The menu provides a fast mechanism to swap the language view. Each language-view shares the concept map but the labels are displayed and modified for the corresponding language. CM-ED allows users to open more that one view simultaneously. In Figure 1 the user has opened one window for the English version of the concept map and another one for the Basque version of the same concept map. There is no pre-eminent language; the user chooses the language s/ he wants to work in.

- Propagation of changes. CM-ED treats differently the operations that the user performs in the view depending on their type. The tool identifies two types of operations: concept map level operations and language-view level operations. On 
the one hand, the CM-level operations, those related to the structure of the CM (insertion or deletion of nodes and relations), are automatically propagated to all the views. For example when the user creates a new node, the tool shows it in all the views. On the other hand, the language-view level operations only apply to one view and, therefore, they are not automatically propagated to the rest of views, for example label modifications, nodes colour changes, spatial distribution of nodes, etc. However, the user can ask the tool to propagate those changes manually.

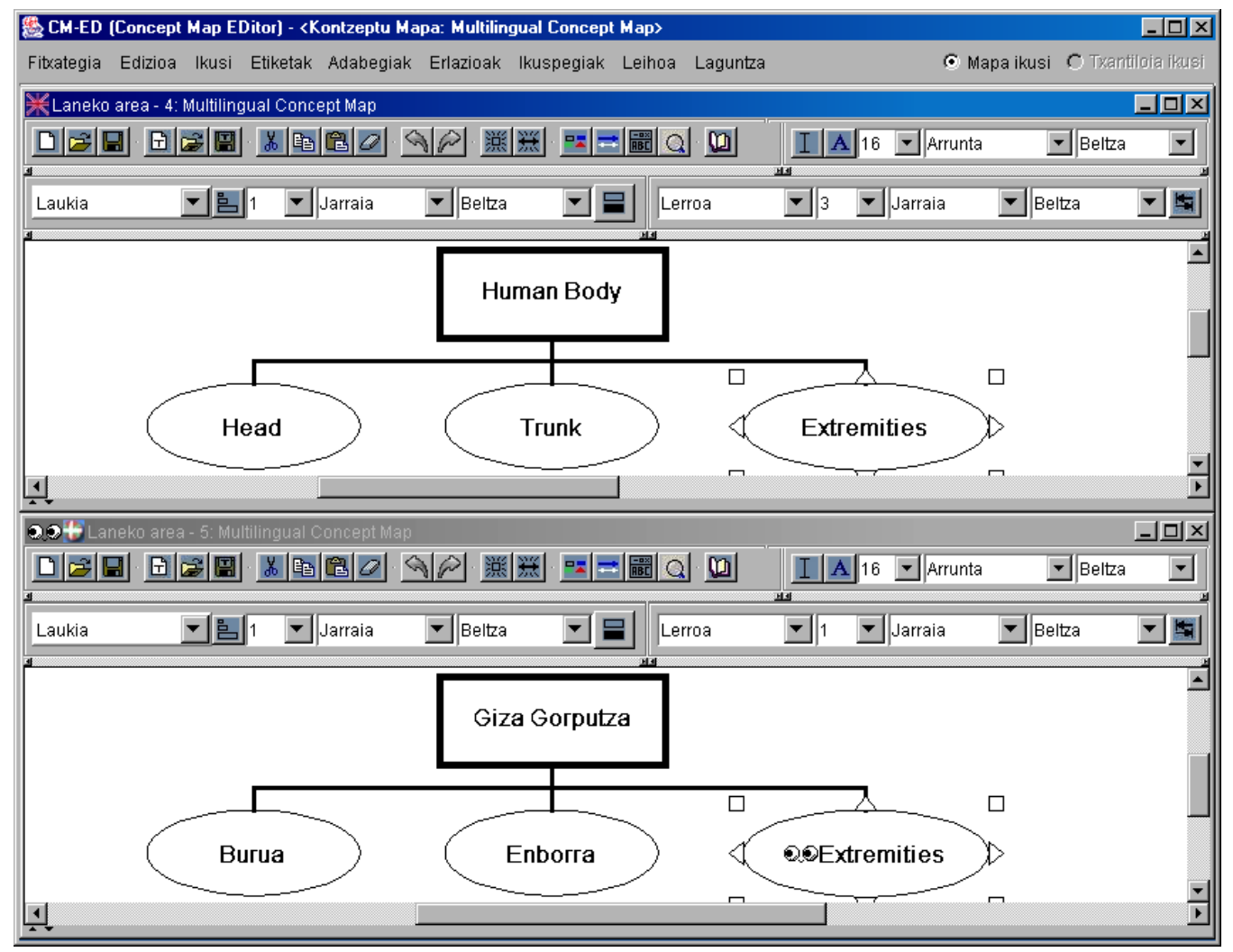

Figure 1: Example of a multilingual concept map

- Control of label changes. The creation of multilingual material is in general an incremental process with some intrinsic difficulties that requires certain effort. When working with multilingual material and in order to maintain the coherence of the target material in all the versions, much more attention is needed. For example, when users are working with CM-ED and they change the label of a node in a particular view of a concept map, they should check if it is necessary or not to localise the label in the rest of views. CM-ED has been designed to help this exhaustive checking. The approach for the control of changes process is based on flags attached not only to nodes/relations but also to views. The propagation of label changes can be triggered automatically or manually. In the automatic case, when the user performs changes on the label of a node/relation the corresponding nodes/relations in the rest of the views are automatically marked with the check label flag (1) 
with the check view flag (\$S) in the internal window title. In Figure 1, the user has created the "Extremities" node in the English version of the concept map, but it is not yet translated in the Basque version. The check label flag on the node/relation disappears automatically when the user changes the marked label. In addition, when all the check label flags disappear from the view, the check view flag also disappears. CM-ED also allows users to set or unset manually a check label when they realise that some label has to be checked or not respectively. Moreover, some operations do not require checking other versions, for example when the user corrects a spelling mistake. In these cases, the user can ask the system not to propagate the check flags.

The control of label changes function is proven to be very helpful when the concept map is rather completed, but at the beginning of the process of creating a map many flags are triggered. In this case it would be more comfortable to work without this help. Taking this fact into account, CM-ED provides the user two modes of working: with or without control of label changes.

- Dictionary. CM-ED includes dictionaries that help in the translation of the labels. A dictionary, in CM-ED, is a two-dimensional table that contains the translations of the labels in different languages. The dictionaries are dynamic, i.e. while working with the tool the corresponding dictionary is updated. On the one hand, the user can update the dictionary directly editing the Dictionary Table (see Figure 2). On the other hand, the dictionary is changed indirectly when the translations that the user performs while constructing concept maps are added to the corresponding dictionary. Each concept map is related to a dictionary, so the changes that happen in the dictionary are automatically propagated to the concept map and highlighted with check label flags (following the control mechanism explained above). In addition, changes in the labels of the concept map are marked in the dictionary using check dictionary flag. The user can profit from the dictionaries in different ways. For example the tool can find the translation of a label to other languages or anticipate the translation of a label if it is in the dictionary.

\begin{tabular}{|c|c|c|c|}
\hline \multicolumn{3}{|l|}{ Sictionary } & \multirow[t]{2}{*}{$\sqrt{x}$} \\
\hline File Add Show & Language & & \\
\hline en & es & eu & \\
\hline Extremities & & & $\Delta$ \\
\hline Head & & Burua & \\
\hline Human Body & & Giza gorputza & \\
\hline Trunk & & Enborra & $\nabla$ \\
\hline
\end{tabular}

Figure 2: Dictionary

\section{Study}

In this section, the conducted study is presented. The design issues, participants, instructors, instructional material, learning resources and procedure are described.

\section{Design}

This study took place in the compulsory Fundamentals of Database Systems course of the Computer Science program at the University of the Basque Country during spring of 
2009. This second course subject is offered in both Basque and Spanish and students can choose the language in which they will take their classes. The study here presented was carried out with students enrolled in Basque language who, due to administrative reasons, were separated into two groups, one of them composed of 6 students and the other one composed of 12 students.

The study has the following three main aims: to facilitate learning about the subject domain, to evaluate whether concept mapping is in general a good technique for learning topics in different languages, and finally, to verify whether CM-ED Concept Map EDitor provides the necessary mechanisms to fulfil this objective. Within the course, the topic Introduction to Databases (Elmasri \& Navathe, 2007a) was chosen for working with CM-ED.

\section{Participants}

A group of 18 students collaborated in the experience. The experimental group -6 students - developed the multilingual concept map and the control group - 12 students - did not develop it. From the two groups of students enrolled in the subject, the group composed of 6 students was randomly chosen as the experimental group.

\section{Instructors}

Two teachers, one PhD researcher and one PhD student participated in the study. Teachers were in charge of teaching the subject. They have been teaching this course for 15 and 8 years respectively and the first one was well trained in drawing and assessing concept maps created both with paper and pencil (P\&P) and with means of computer software. The PhD researcher (developer of CM-ED) and the PhD student were in charge of assisting students with technical issues.

\section{Instructional materials}

A 25 slides document written in Basque language that contains a summary of the main concepts and ideas underlying the worked topic and two bibliographical references in English (Elmasri \& Navathe, 2007a) and in Spanish (Elmasri \& Navathe, 2007b) constituted the instructional material for the Introduction to Databases topic. Students were also provided with handouts that included an introduction to concept mapping, examples of well constructed concept maps, instructions for downloading and installing the software, and an online user guide. Initially, no human assistance about the CM-ED editor was provided to participants (only the online user's guide).

\section{Procedure}

The study was carried out in eight phases: (1) content teaching sessions, (2) study presentation, (3) concept maps development, (4) concept maps collection, (5) posttesting, (6) concepts translation test, (7) final exam and, finally, (8) repetition of concepts translation test. Next each phase is described:

1. Content teaching sessions. Students received two introductory sessions on the Introduction to Databases topic, each lasting 60 minuites. The subject teacher oversaw this activity. 
2. Study presentation. One session was used by the teacher to briefly introduce the concept mapping technique, provide some examples of well constructed concept maps, briefly describe the main characteristics of CM-ED, and show the main aim and guidelines for the study's phases.

3. Concept maps development. Students had five weeks to work on their concept maps before maps were submitted. Students were asked to draw, individually and from scratch, the multilingual concept map of the topic. Students chose the languages they wanted to use from Basque, English, and Spanish. The content and structure of the maps was the same but each one was written in a different language. During this period, students worked autonomously, but both the course teacher and the technical instructors were available in case assistance was needed. However, no technical support was required during the experiment.

4. Final concept map collection. The teacher collected the concept maps from 6 students, assessed them and selected some of them to discuss with students during a 30 minute course session. Figure 3 shows a concept map developed in the study. Taking into account that this paper is written in English, both examples are drawn from the English version of the concept maps.

5. Post-testing. During a 20 minute session, students who developed the concept maps completed a questionnaire composed by 28 questions. The test allowed participants to give their opinion about: interest they had in the study, preferred learning method, experience with concept maps in general and with concept map software in particular, subject learning, quality of the created maps, multilingual subject terminology learning, concept mapping technique learning, usefulness of the concept mapping technique for learning purposes in general and for learning database concepts in particular, CM-ED learning, the utility of CM-ED, usefulness of working with multilingual concept maps for learning purposes, usefulness of features included in CM-ED for working concept maps in general and multilingual concept maps in particular, opinion about the features of CM-ED, whether it is easy to use or not, problems encountered during the study, and some open-ended questions asking for general feedback.

6. Concepts translation test. During a 10 minute session the students in both the experimental and control groups were asked to translate 10 concepts related to databases from Basque to English and to Spanish.

7. Final exam. It took place seven weeks after collecting the final concept maps. The final exam's test part was composed of 21 questions, 4 of them being taken from the Introduction to Databases topic.

8. Repetition of concepts translation test. Together with the final exam, students who participated in developing the concept maps (experimental group) were asked to translate the same 10 concepts related to databases from Basque to English and to Spanish. The aim was to verify whether the obtained learning level in phase 6 was maintained over time. 


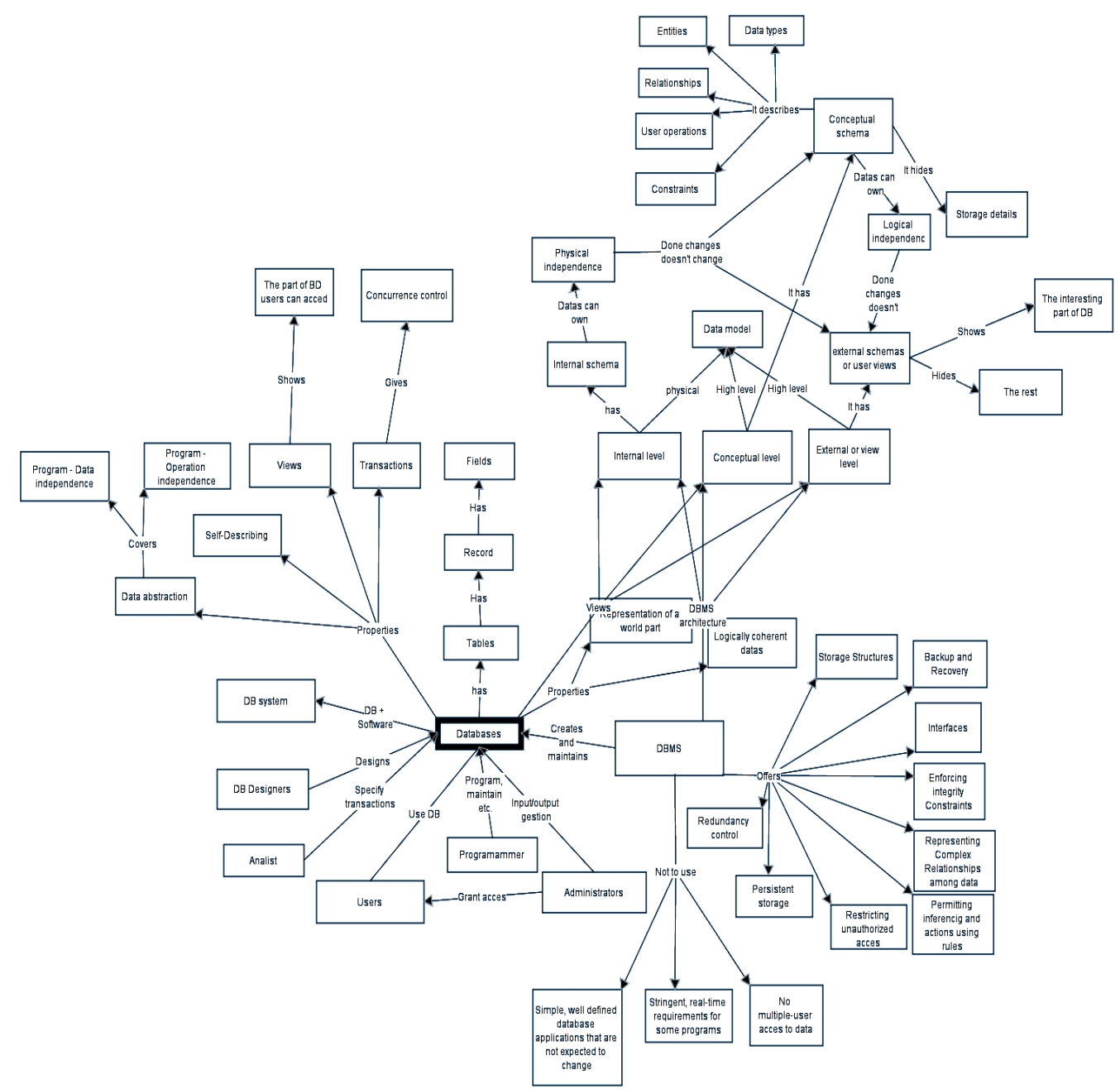

Figure 3: Example of an English version concept map drawn using CM-ED (see Appendix for a higher resolution image)

\section{Results and discussion}

After analysis of both the collected concept maps and the students' data (questionnaire, translation tests and exam) we found the results to be positive in several dimensions: subject domain learning outcome, terminology learning in different languages, and CM-ED usefulness in this multilingual learning setting. The quality of the generated concept maps was, in general, satisfactory. Even more, participants recognised that although they were not familiar with the concept mapping technique before the experience, concept mapping is a good technique, not only for learning topics about a domain and their relationships but also to learn domain terminology in different languages. They had a good opinion about the CM-ED software in general and, in particular, about the mechanisms it provides for working multilingual concept maps. Participants were happy with their participation in this 
study and showed interest in future experiences for evaluating software for educational purposes.

The results obtained in this study are divided into three main groups: learning of the subject domain, learning of the subject terminology in different languages, and CM-ED appropriateness for working with multilingual concept maps.

\section{Results for subject domain learning}

Three sources of data have been used to evaluate the domain acquisition of the students: the opinions students had about how much they learned about the subject domain, the assessment of the generated concept maps, and the final exam questions that related to the subject domain.

Students in the experimental group were asked whether or not they learned the concept mapping technique and whether or not they considered concept mapping a good technique for learning new subject domains. Before taking part in the study, only $16.7 \%$ of students were familiar with the concept mapping technique. Nevertheless, after the participation, the whole group (100\%) claimed to be able to work with this technique. Even more, $83.3 \%$ recognised that concept mapping strategy is as good as summary or schema techniques for learning purposes. $83.3 \%$ of students were convinced that while creating the concept map they learned the subject domain. Considering these results, concept mapping training should be reinforced.

Regarding the quality of the generated concept maps, teachers admit that all of them were clear, and showed synthesis capability and adequate topic identification. Concerning relationships identification, $83.3 \%$ identified and labelled relationships adequately; the $16.7 \%$ established relationships but did not include any text label. The average number of topics identified in the concept maps was 44, and the average number of relationships was 28 (20.9 binary and $7.2 \mathrm{n}$-ary). Authors have found this flaw in other experiments and think that students are more conscious of the concept than the relationships. They may know that concepts are linked but do not care about naming the links. Therefore, it is clear that previous training in concept mapping should transmit to the students the importance of knowing about the semantics of the relationships.

Four questions related to the topic were included in the 21 questions in the final exam. The average correct item rate for the experimental group was 3.3 and 2.1 for the control group. A t-test analysis confirmed this finding to be statistically significant $(p<0.012)$. More detailed results for the four topic-related questions are shown in Table 1. Students who created a concept map scored much better on those four questions and thus, the construction of concept maps helped to better consolidate their knowledge. It must be pointed out that no statistically significant differences were found for other questions in the final exam. Those results are consistent with some findings in nontechnical subjects (Rueda et al. 2009).

Table 1: Results of the four topic-related questions in the final exam

\begin{tabular}{|l|c|c|c|}
\hline & $\begin{array}{c}1-2 \text { correct } \\
\text { answers }\end{array}$ & $\begin{array}{c}3-4 \text { correct } \\
\text { answers }\end{array}$ & $\begin{array}{c}\text { Average mark } \\
\text { on the 4 items }\end{array}$ \\
\hline Experimental group & $0 \%$ & $100 \%$ & 3.3 \\
\hline Control group & $83.3 \%$ & $16.7 \%$ & 2.1 \\
\hline
\end{tabular}




\section{Results on learning domain terminology in different languages}

The main aim of this study was to promote the multilingual learning (Basque, English and Spanish languages) of technical topics related to Database Introduction through the use of concept maps. As said before students chose the languages they wanted to use. All the participants created the concept map in Basque (their native language). Three students developed the concept map in the three languages, two using Basque and Spanish and one Basque and English. Summarising, the experimental group produced nine translations of the concept map in other than the native language of the students.

The data analysed in this section came from the concepts translation test (Phase 6 above), in which students were asked to translate 10 concepts from Basque into English and Spanish. Table 2 shows the chosen ten topics and their translation into the three languages.

Table 2: Ten chosen topics and their translation

\begin{tabular}{|c|l|l|l|}
\hline No. & \multicolumn{1}{|c|}{ Basque } & \multicolumn{1}{|c|}{ English } & \multicolumn{1}{c|}{ Spanish } \\
\hline 1 & Datu-base kudeaketa sistema & $\begin{array}{l}\text { Database management } \\
\text { system }\end{array}$ & $\begin{array}{l}\text { Sistema de gestión de bases } \\
\text { de datos }\end{array}$ \\
\hline 2 & Datu-eredu & Data model & Modelo de datos \\
\hline 3 & Biltegigailu & Storage medium & $\begin{array}{l}\text { Dispositivo de } \\
\text { almacenamiento }\end{array}$ \\
\hline 4 & Integritate-murriztapen & Integrity constraint & Restricción de integridad \\
\hline 5 & Datu-definizio lengoaia & Data definition language & $\begin{array}{l}\text { Lenguaje de definición de } \\
\text { datos }\end{array}$ \\
\hline 6 & Ikuspegi & View & Vista \\
\hline 7 & $\begin{array}{l}\text { Datuen independentzia } \\
\text { logikoa }\end{array}$ & Logical data independence & $\begin{array}{l}\text { Independencia lógica de } \\
\text { datos }\end{array}$ \\
\hline 8 & Fitxategi & File & Fichero \\
\hline 9 & Hiru eskemako arkitektura & Three-schema architecture & $\begin{array}{l}\text { Arquitectura de tres } \\
\text { esquemas }\end{array}$ \\
\hline 10 & Kanpo-maila & External level & Nivel externo \\
\hline
\end{tabular}

Data gathered in the experiment suggest that students who developed the concept maps in one language translated the topics more accurately in that language than students belonging to the control group. The average correct translation rate of the students of the experimental group reached $91.1 \%$ while the average score of the control group was $34.6 \%$. A t-test analysis of the data confirms this result $(\mathrm{p}<0.01)$, and the findings are consistent with results from other authors' work on second language learning (Chularut \& DeBacker, 2004; Bahr \& Dansereau, 2004).

After analysing the translation accuracy, differences between words were found. For example non-specific terms like file obtained very high correct translation probably because students knew the word previously. Another reason could be the fact that the translation of the topic file is not very different in the three languages (fitxategia - file fichero). However, the topic storage medium, that is also not specific to databases area, obtained the worst results. In this case the translation is quite different (biltegigailu storage medium - dispositivo de almacenamiento). Therefore two reasons may explain the differences: specificity of the term and similarity between languages.

After seven weeks and together with the final exam, students who worked the concept maps were asked to translate, again, the same ten topics from Basque to English and to 
Spanish (Phase 8). Results verified that the learning level obtained in Phase 6 was, in general, maintained along the time. Students kept their translation accuracy level with a deviation of $-1 /+1$ word. Those results show that the student really learnt the terminology in the other languages and that learning was not volatile. This is consistent with Ausubel's theory of meaningful learning in which concept maps are based on.

\section{Evaluation of aids for multilingual concept mapping in CM-ED}

The data analysed in this section came from the post-test questionnaire completed by students. All the participants recognised the importance that multilingualism has in the current society and admitted the necessity of developing software tools that allows working with multilingual aspects not only at user interface level but also in the final products of the software. For example, one Basque native student stated that "there is very few software with the interface localised to Basque language" (translated by the authors). All the participants agreed that CM-ED provides enough mechanisms to develop multilingual concept maps. Another student remarked that "the eyes are very useful not to get lost in translating the map" (translated by the authors). Nevertheless, instructors want to remark that participants only used two of the mechanisms provided by CM-ED for working multilingual concept maps: simultaneous work with different versions and automatic propagation of changes. This fact suggests that it is not enough a brief presentation of CM-ED, instead a deeper training would be beneficial to use all the functionality that the tool offers.

\section{Conclusions}

Traditionally in the educational area, concept mapping has not been used as a technique to promote multilingual learning. The aims of this study were: to facilitate learning about the subject domain, to evaluate whether concept mapping is in general a good technique for learning topics in different languages, and finally, to verify whether CM-ED Concept Map EDitor provides the necessary mechanisms simultaneous work with different versions, the propagation of changes, the control of changes, and the dictionary - to fulfil those objectives.

The outcomes of the study are summarised below:

- The most important conclusion is that students who studied the subject domain using concept maps showed better translation ability with technical words.

- In addition, the students who developed the concept maps obtained better results in the questions related to the worked subject in the final exam.

- From the students' point of view, CM-ED provided the necessary mechanisms for working with multilingual concept maps. Although, in general, computer science students had no problems working with CM-ED without any human assistance (they were provided with only an online user's guide), the authors think that it would be helpful to provide more assistance in order to get a better use of all the mechanisms provided by the tool.

- Students not previously familiar with concept mapping techniques agreed that the experience helped them to know how to use concept maps as a learning strategy. 
The main limitation in this study is the small number of students. In addition, it was not easy to maintain the engagement level of the students due to the long duration of the study; it took one complete term. However, it should be pointed out students did not report any problems answering the questionnaires and they did not ask for help during the experiment.

Considering the positive results, the authors argue that this technology can help in bilingual and multilingual education settings. Further, larger experiments and real deployments are likely to show needs for other specialised, technology-based educational tools. The challenge is large, and therefore any aids or tools that will bring us closer to the goal need to be considered. As said before, governments are becoming more conscious that it is necessary to deal better with diversity in language, culture and identity, and that bigger efforts are needed in this direction.

Following this research line - promotion of multilingual education in computer science - some other works are being put in practice. For example, during the spring of 2012 a similar study is in proress. This time students individually drew concept maps for the same topic, Introduction to the Databases, in their own language (Basque or Spanish), and after that they worked collaboratively to construct a consensus concept map in English. In addition, several experiences of using CM-ED both individually and collaboratively have been developed in technical - e.g. artificial intelligence (Arruarte et al., 2008) - and non-technical subjects - e.g. psychology (Rueda et al., 2009; Elorriaga et al., 2011).

Currently, the authors' work is focused on the identification of differences in crosscultural perception and understanding of concept mapping, in particular identifying aspects of concept map design (beyond text and label translation design issues) that are culturally sensitive (color, icons, etc.), with the aim of providing CM-ED with enhancments to work with such cross-cultural aspects.

\section{Acknowledgments}

This work has been partially supported by the Spanish Ministry of Education, grant TIN2009-14380, the University of the Basque Country UPV/EHU, grant (EHU09/09) and the Basque Government, grant IT421-10.

\section{Appendix}

The appendix, a higher resolution version of Figure 3: Example of an English version concept map drawn using CM-ED, is available in an accompanying file, URL http://www.ascilite.org.au/ajet/ajet28/arruarte5.jpg

\section{References}

Afamasaga-Fuata'i, K. (2004). Concepts maps \& vee diagrams as tools for learning new mathematics topics. In A. J. Cañas, J. D. Novak \& F. M. González (Eds), Concept maps: Theory, methodology, technology. Proceedings of the First International Conference on Concept Mapping. Universidad Pública de Navarra, 13-20. http: / / cmc.ihmc.us / papers/cmc2004-271.pdf

Anderson-Inman, L., Ditson, L. \& Ditson, M. (1998). Computer-based concept mapping: Promoting meaningful learning in science for students with disabilities. Information Technologies and Disabilities Journal, Special K-12 issue, article 2. http: / / people.rit.edu/ easi/itd/itdv5n12/article2.htm 
Arbea, J., Santos, P. \& Abascal, S. (2004). The application of computer-made concepts maps to the organization of information: A Comenius Project. In A. J. Cañas, J. D. Novak \& F. M. González (Eds), Concept maps: Theory, methodology, technology. Proceedings of the First International Conference on Concept Mapping. Universidad Pública de Navarra, 49-52. http: / / cmc.ihmc.us/ papers/ cmc2004-147.pdf

Arruarte, A., Rueda, U. \& Elorriaga, J. A. (2008). Organizing the learning resources related to the subject Introduction to Artificial Intelligence through Concept Maps. In 38th Annual Frontiers in Education Conference FIE2008 (pp. F1C-17 - F1C-22). http: / / dx.doi.org/ 10.1109/ FIE.2008.4720484

Austin, L. B. \& Shore, B. M. (1995). Using concept mapping for assessment in physics. Physics Education, 30(1), 41-45.

Ausubel, D. P. (1968). Educational psychology: A cognitive view. Holt, Rinehart and Winston.

Ausubel, D. P., Novak, J. D. \& Hanesian, H. (1978). Educational psychology: A cognitive view. 2nd edition. New York: Holt, Rinehart and Winston.

Bahr, G. S. \& Dansereau, D. F. (2004). Bilingual knowledge (BIK-) maps: Study strategy effects. In A. J. Cañas, J. D. Novak \& F. M. González (Eds), Concept maps: Theory, methodology, technology. Proceedings of the First International Conference on Concept Mapping, UPNA,, pp. 5966, Universidad Pública de Navarra. http: / / cmc.ihmc.us/ papers/cmc2004-100.pdf

Bahr, G. S. \& Dansereau, D. F. (2005). Bilingual knowledge maps (BiK maps) as a presentation format: Delayed recall and training effects. The Journal of Experimental Education, 73(2), 101118. http:/ / www.jstor.org/ discover/10.2307/ 20157389

Brandt, L., Ellen, J., Hellemans, J., Heerman, L., Couwenberg, I., Volckaert, L. \& Morisse, H. (2001). The impact of concept mapping and visualization on the learning of secondary school chemistry students. International Journal of Science Education, 23(12), 1303-1313. [verified 22 May 2012] http: / / www.stanford.edu/dept/SUSE/ projects/ireport/articles/concept_maps / the $\% 20 \mathrm{impact} \% 20 \mathrm{of} \% 20 \mathrm{visual} \% 20$ concept $\% 20 \mathrm{map}$.pdf

Calvo, I., Arruarte, A., Elorriaga, J. A., Larrañaga, M. \& Conde, A. (2011). The use of concept maps in computer engineering education to promote meaningful learning, creativity and collaboration. In Proceedings of the 41st Frontiers in Education Conference FIE2011, pp.T4G-1 T4G-6. http: / / dx.doi.org/10.1109/FIE.2011.6142762

Carnot, M. J. (2006). Using concept maps to organize information for large scale literature reviews and technical reports: Two case studies. In A. J. Cañas \& J. D. Novak (Eds), Concept maps: Theory, methodology, technology. Proceedings of the Second International Conference on Concept Mapping, pp. 275-278. http:/ / cmc.ihmc.us / cmc2006Papers/ cmc2006-p225.pdf

Chularut, P. \& DeBacker, T. (2004). The influence of concept mapping on achievement, selfregulation, and self-efficacy in students of English as a second language. Contemporary Educational Psychology, 29(3), 248-263. http:/ / dx.doi.org/10.1016/j.cedpsych.2003.09.001

Cicognani, A. (2000). Concept mapping as a collaborative tool for enhanced online learning. Educational Technology E Society, 3(3), 150-158. http:/ / www.ifets.info/journals/3_3/b01.html

Dabbagh, N. (2001). Concept mapping as a mindtool for critical thinking. Journal of Computing in Teacher Education, 17(2), 16-24. http:/ / www.iste.org/Store/Product.aspx?ID=1937

Esiobu, G. \& Soyibo, K. (1995). Effects of concept and vee mapping under three learning modes on students' cognitive achievement in ecology and genetics. Journal of Research in Science Teaching, 32(9), 971-995. http:/ / dx.doi.org/10.1002/ tea.3660320908

Elmasri, R. \& Navathe, S. B. (2007a). Fundamental of database systems. Fifth Edition, Boston: Pearson International Edition. 
Elmasri, R. \& Navathe, S. B. (2007b). Fundamentos de sistemas de bases de datos. Quinta Edición, Madrid: Pearson, Addison Wesley.

Elorriaga, J. A., Arruarte, A., Calvo, I., Larrañaga, M., Rueda, U. \& Herran, E. (2011). Collaborative concept mapping activities in a classroom scenario. Behaviour $\mathcal{E}$ Information Technology, (iFirst). http:/ / dx.doi.org/10.1080/0144929X.2011.632649

Gul, R. B. \& Boman, J. A. (2006). Concept mapping: A strategy for teaching and evaluation in nursing education. Nurse Education in Practice, 6(4), 199-206. http: / / dx.doi.org/10.1016/j.nepr.2006.01.001

Hsu, L. \& Hsieh, S. (2005). Concept maps as an assessment tool in a nursing course. Journal of Professional Nursing, 21(3), 141-149. http:/ / dx.doi.org/10.1016/j.profnurs.2005.04.006

Jonassen, D. H., Reeves, T. C., Hong, M., Harvey, D. \& Peters, K. (1997). Concept mapping as cognitive learning and assessment tools. Journal of Interactive Learning Research, 8(3-4), 289308. http: / / dl.acm.org/ citation.cfm?id=313725

Kwon, S. Y. \& Cifuentes, L. (2009). The comparative effect of individually-constructed vs. collaboratively-constructed computer-based concept maps. Computers $\mathcal{E}$ Education, 52(2), 365375. http:/ / dx.doi.org/10.1016/j.compedu.2008.09.012

Laight, D. W. (2004). Attitudes to concept maps as a teaching/learning activity in undergraduate health professional education: Influence of preferred learning style. Medical Teacher, 26(3), 229-233. http: / / dx.doi.org/10.1080/0142159042000192064

Mahnam, L. \& Nejadansari, D. (2012). The effects of different pre-writing strategies on Iranian EFL writing achivement. International Education Studies, 5(1), 154-160. http:/ / dx.doi.org/10.5539/ies.v5n1p154

Marangos, J. \& Alley, S. (2007). Effectiveness of concept maps in economics: Evidence from Australia and USA. Learning and Individual Differences, 17(2), 193-199. http: / / dx.doi.org/10.1016/j.lindif.2007.03.003

Marchand, C., d'Ivernois, J. F., Assal, J. P., Slama, G. \& Hivon, R. (2002). An analysis, using concept mapping, of diabetic patients' knowledge, before and after patient education. Medical Teacher, 24(1), pp. 90-99. http:/ / dx.doi.org/10.1080/01421590120091087

Moreira, M. \& Moreira, S. (2011). Meaningful learning: Use of concept maps in foreign language education. Aprendizagem Significativa em Revista/Meaningful Learning Review, 1(2), 64-75. http: / / www.if.ufrgs.br/asr/artigos / Artigo_ID11/v1_n2_a2011.pdf

Novak, J. D. (1977). A theory of education. Ithaca, NY: Cornell University.

Novak, J. D. (1992). The theory underlying concept maps and how to construct them. Cornell University.

Novak, J. D. \& Cañas, A. J. (2008). The theory underlying concept maps and how to construct and use them. Technical Report IHMC CmapTools 2006-01 Rev 01-2008, Florida, Institute for Human and Machine Cognition. [verified 23 May 2012] http: / / cmap.ihmc.us / Publications / ResearchPapers/TheoryUnderlyingConceptMaps.pdf

Reza, M. \& Mousapour, G. (2009). The effect of explicit teaching of concept mapping in expository writing on EFL students' self-regulation. Research in Contemporary World Literature, 13(49), 85-108. http:/ / journals.ut.ac.ir/page/ download-vHe1OoQ1cGA.artdl

Roberts, L. (1999). Using concept maps to measure statistical understanding. International Journal of Mathematical Education in Science E Technology, 30(5), 707-717. http: / / dx.doi.org/ 10.1080/002073999287707 
Rueda, U., Arruarte, A., Elorriaga, J. A. \& Herrán, E. (2009). Learning the attachment theory with the CM-ED concept map editor. Computers \& Education, 52(4), 460-469.

http: / / dx.doi.org/10.1016/j.compedu.2008.09.015

Ruiz-Primo, M. A. (2004). Examining concept maps as an assessment tool. In A. J. Cañas, J. D. Novak \& F. M. González (Eds), Concept maps: Theory, methodology, technology. Proceedings of the First International Conference on Concept Mapping. Vol. I. Universidad Pública de Navarra pp. 555-562. http:/ / cmc.ihmc.us/ papers / cmc2004-036.pdf

Saadati, Z. (2011). The impact of fill-in-the-map and construct-a-map techniques on EFL learners' use of tenses in oral accuracy. European Journal of Social Sciences, 22(2), 299-308. http:/ / www.eurojournals.com/EJSS_22_2_14.pdf

Stoddart T., Abrams, R., Gasper, E. \& Canaday, D. (2000). Concept maps as assessment in science inquiry learning - a report of methodology. International Journal of Science Education, 22(12), 1221-1246. http:/ / dx.doi.org/10.1080/095006900750036235

Taber, K. S. (1994). Student reaction on being introduced to concept mapping. Physics Education, 29(5), 276-281. http: / / dx.doi.org/10.1088/0031-9120/29/5/003

Tekkaya, C. (2003). Remediating high school students' misconceptions concerning diffusion and osmosis through concept mapping and conceptual change text. Research in Science $\mathcal{E}$ Technological Education, 21(1), 5-16. http: / / dx.doi.org/10.1080/02635140308340

Trong, L. \& Bich, L. T. (2011). The linkages between concept maps and language learning. Studies in Literature and Languages, 2(1), 128-146.

http: / / cscanada.net/index.php/sll/article/view/j.sll.1923156320110201.005/1480

Unesco (2003). Education in a multilingual world. United Nations Educational, Scientific and Cultural Organization, Paris (France) [ED-2003/WS/2].

http: / / unesdoc.unesco.org/images/0012/001297/129728e.pdf

Wilson, G., Nash, M. \& Earl, G. (2010). supporting students with language learning difficulties in secondary schools through collaboration: The use of concept maps to investigate the impact on teachers' knowledge of vocabulary teaching. Child Language Teaching and Therapy, 26(2), 163-179. http: / / dx.doi.org/10.1177/0265659010368749

Authors: Ana Arruarte, Jon A. Elorriaga (contact author: Email: jon.elorriaga@ehu.es), Iñaki Calvo, Mikel Larrañaga

Computer Languages and Systems Department

University of the Basque Country (UPV/EHU)

Informatika Fakultatea, Manuel de Lardizabal 1,

Donostia, Basque Country, E-20018, Spain.

Urko Rueda, ProS Research Center, Universitat Politècnica de València

Camíno de Vera, s/n 46022 Valencia, Spain.

Please cite as: Arruarte, A., Elorriaga, J. A., Calvo, I., Larrañaga, M. \& Rueda, U.

(2012). Computer-based concept maps for enabling multilingual education in

computer science: A Basque, English and Spanish languages case. Australasian Journal of Educational Technology, 28(5), 793-808.

http: / / www.ascilite.org.au/ajet/ajet28/arruarte.html 